\title{
Recurrent Visual Pathway Glioma
}

National Cancer Institute

\section{Source}

National Cancer Institute. Recurrent Visual Pathway Glioma. NCI Thesaurus. Code C155983.

The reemergence of visual pathway glioma after a period of remission. 